\title{
CONTRASTES BARITADOS: A TOXICOLOGIA EXPERIMENTAL COMO FERRAMENTA NO ESTABELECIMENTO DE NEXO CAUSAL DE INTOXICAÇÃO MACIÇA POR BÁRIO
}

\section{Barium-containing contrasts: the experimental toxicology as tool in the establishment of causal nexus of massive poisoning for barium compounds}

\author{
Luiz C. Cunha ${ }^{1 *}$, Rodrigo B. Oliveira ${ }^{2}$, Flaubertt S. Azeredo ${ }^{2}$, Marize C. Valadares ${ }^{1}$ \\ ${ }^{1}$ Núcleo de Estudos e Pesquisas Tóxico-Farmacológicas (NEPET-UFG). Faculdade de Farmácia, Universidade \\ Federal de Goiás. Praça Universitária s/n. 74605-220. Goiânia-GO, Brasil. \\ ${ }^{2}$ Aluno de Mestrado em Ciências Farmacêuticas da Faculdade de Farmácia, Universidade Federal de Goiás. \\ Praça Universitária s/n. 74605-220. Goiânia-GO, Brasil.
}

*Autor para correspondência e-mail: Iccunha@farmacia.ufg.br

Recebido em 12/11/2006 - Aceito em 15/12/2006

RESUMO: Em abril de 2003, a Vigilância Sanitária do Estado de Goiás (VISA-GO) começou a receber notificações acerca de possível intoxicação pelos contrastes radiológicos marcas A, B e C. Estes medicamentos são suspensões de sulfato de bário em água $\left(B^{2} \mathrm{SO}_{4} 1 \mathrm{~g} / \mathrm{ml}\right)$, que não sofrem absorção no trato gastrintestinal, pois o sulfato de bário é insolúvel em água, apresentando baixíssima absorção. De um total de 223 casos investigados, 44 pacientes (20\%) foram considerados suspeitos de intoxicação. Destes, 11 (26\%) foram hospitalizados e 9 (21\%) foram a óbito devido à utilização do medicamento Marca A em Goiás, até 24 h após a exposição. Os principais sinais e sintomas de intoxicação foram: náusea, dor abdominal, diarréia, vômito, cefaléia, dispnéia, arritmias cardíacas e agitação. Das três marcas de contraste à base de bário envolvidas, uma delas (Marca A), esteve associada a 89\% das mortes de pacientes. No presente artigo, investigou-se a toxicidade aguda (screening hipocrático, letalidade) do produto Marca A, comparando-o a outros sais de bário solúveis (nitrato, $\mathrm{Ba}\left(\mathrm{NO}_{3}\right)_{2}$ e carbonato de bário, $\left.\mathrm{Ba}\left(\mathrm{CO}_{3}\right)_{2}\right)$ e insolúvel (sulfato de bário puro), pois o produto Marca $\mathrm{A}$ estava contaminado com 13,8\% de carbonato de bário. Material e Métodos: utilizaram-se camundongos Swiss machos, pesando em média $25 \mathrm{~g}$ e ratos Wistar, machos (300-430 g) alojados em gaiolas de polipropileno com água e ração a vontade. Utilizaram-se 2 a 3 ratos/dose, via gavage. Utilizaram-se 7 grupos de 10 camundongos com doses p.o., além do controle. Todos os animais foram observados por até 14 dias; os sobreviventes foram sacrificados e avaliados anátomo-patologicamente. Animais controle receberam solução salina fisiológica e sem tratamento algum. Resultados: os ratos tratados com $\mathrm{Ba}\left(\mathrm{NO}_{3}\right)_{2}, \mathrm{Ba}\left(\mathrm{CO}_{3}\right)_{2}$ e Marca $\mathrm{A}$ apresentaram sinais de intoxicação, dose-dependentes: tremores, eriçamento de pelo, rinorréia, taquicardia, taquipnéia, diarréia, diminuição reflexo de endireitamento, flacidez e paralisia muscular, pênis e testículos proeminentes e inflamados, morte $(50 \%$ dos animais tratados com Marca A). Os ratos tratados com sulfato de bário puro mantiveram-se normais. Letalidade observada: $\mathrm{Ba}\left(\mathrm{NO}_{3}\right)_{2}(800 \mathrm{mg} / \mathrm{kg}), \mathrm{Ba}\left(\mathrm{CO}_{3}\right)_{2}(2000 \mathrm{mg} / \mathrm{kg})$ e Marca A $(2000 \mathrm{e} 4000 \mathrm{mg} / \mathrm{kg})$. Nenhuma morte por $\mathrm{BaSO}_{4}$ observada. Para os camundongos, as doses de 1000 e $2000 \mathrm{mg} / \mathrm{kg}$ foram letais para $10 \%$ dos animais e a dose de $4000 \mathrm{mg} / \mathrm{kg}$ levou à letalidade $50 \%$ dos animais.

PALAVRAS-CHAVE: bário, contraste, toxicidade aguda.

ABSTRACT: On April, 2003, the Sanitary Surveillance of the State of Goiás (VISA-GO) started to receive notifications concerning possible poisoning Barium-containing contrast pharmaceutical products of brand $A, B$ and C. These contrast solutions should be barium sulphate suspensions in water $\left(\mathrm{BaSO}_{4} 1 \mathrm{~g} / \mathrm{ml}\right)$, which is not absorbed by the gastrointestinal tract. Two hundred twenty three (223) cases were investigated, in which 44 patients (20\%) were considered poisoning. Of these, $11(26 \%)$ were hospitalized and $9(21 \%)$ died due to the brand A contrast solution, $24 \mathrm{~h}$ after the exposition. The main signals and symptoms were: nausea, abdominal pain, diarrhea, vomiting, cardiac arrhythmias, chronic headache, dyspnea, and agitation. Of the three brand contrast solution, brand A was associated to $89 \%$ of the deaths. In the present work, we investigated the acute toxicity (hippocratic screening and lethality) of the brand A contrast solution, containing $13,8 \%$ of barium carbonate, in comparison to soluble barium nitrate, $\mathrm{Ba}\left(\mathrm{NO}_{3}\right)_{2}$ and barium carbonate $\left.\mathrm{Ba}\left(\mathrm{CO}_{3}\right)_{2}\right)$ and, insoluble (pure barium sulphate). Material 
and Methods: in was used in the experiments male Swiss mice, weighing $25 \mathrm{~g}$ ( $\mathrm{n}=10$ mice/group) and male Wistar rats, (300-430 g) ( $\mathrm{n}=2$ or 3 rats/dose) kept in polypropylene box with chow and drinking water ad libitum. All animals were observed for 14 days; the survivors were sacrificed and anatomopathologic investigated. Control animals received saline solution only. Results: treatment with $\mathrm{Ba}\left(\mathrm{NO}_{3}\right)_{2}, \mathrm{Ba}\left(\mathrm{CO}_{3}\right)_{2}$ and brand $\mathrm{A}$ produced poisoning signals, in a dose-dependent manner: tremors, rhinorrhea, cardiac arrhythmias, piloerection, diarrhea, decrease in motor activity and respiratory rate, paralysis of skeletal muscle, inflammation of penis and testicles, death $(50 \%$ of the animals treated with brand $A)$. When the animals were treated with pure barium sulphate no toxic effects were observed. Lethality: $\mathrm{Ba}\left(\mathrm{NO}_{3}\right)_{2}(800 \mathrm{mg} / \mathrm{kg}), \mathrm{Ba}\left(\mathrm{CO}_{3}\right)_{2}(2000 \mathrm{mg} / \mathrm{kg})$ and brand $\mathrm{A}(2000$ and 4000 $\mathrm{mg} / \mathrm{kg}$ ). No death was observed for BaSO4. Mice treated with the doses of 1000, 2000 and $4000 \mathrm{mg} / \mathrm{kg}, 10,10$ and $50 \%$ of the animals died, respectively.

KEYWORDS: barium, radiological contrast, acute toxicity.

\section{INTRODUÇÃO}

Em abril de 2003, a Vigilância Sanitária do Estado de Goiás (VISA-GO) começou a receber notificações acerca de possível intoxicação pelos contrastes radiológicos marcas A, B e C. Estes medicamentos são suspensões de sulfato de bário em água $\left(\mathrm{BaSO}_{4} 1 \mathrm{~g} / \mathrm{ml}\right)$, que não sofrem absorção no trato gastrintestinal, pois o sulfato de bário é insolúvel em água e não se dissocia nesse meio, o que impede a sua absorção, aumentando sua segurança. Um total de 223 casos foram investigados e relacionados à exposição ao contraste radiológico, sendo que 44 pacientes (20\%) foram considerados suspeitos de intoxicação. Destes, 11 (26\%) foram hospitalizados e 9 (21\%) foram a óbito devido à utilização do medicamento Marca A em Goiás, até 24 h após a exposição. Os principais sinais e sintomas de intoxicação foram: náusea, dor abdominal, diarréia, vômito, cefaléia, dispnéia, arritmias cardíacas e agitação. Das três marcas de contraste à base de bário envolvidas, uma delas (Marca A), esteve associada a 89\% das mortes de pacientes (CDC-MMWR, 2003).

Soluções contendo bário são frequentemente utilizadas em estudos radiológicos. Outros sais de bário como o nitrato de bário, $\mathrm{Ba}\left(\mathrm{NO}_{3}\right)_{2}$, e carbonato de bário, $\mathrm{Ba}\left(\mathrm{CO}_{3}\right)_{2}$, são solúveis em água e se dissociam neste meio e, portanto, são absorvidos no trato gastrintestinal, provocando intoxicação.

O bário $\left(\mathrm{Ba}^{+2}\right)$ é um denso elemento químico da família $2 \mathrm{~A}$ da Tabela Periódica dos Elementos, que ocorre na natureza sob a forma de cátion divalente em combinação com outros elementos. Existe distribuído na crosta terrestre, na água e no ar (poluição industrial) (IPCS-INCHEM, 2002).

$\mathrm{O}$ sulfato de bário $\left(\mathrm{BaSO}_{4}\right)$ existe como pó branco ortorrômbico ou cristais. A barita, o mineral do qual o $\mathrm{BaSO}_{4}$ é produzido é moderadamente cristalino opaco a transparente. As impurezas mais importantes são o óxido férrico, o óxido de alumínio, a sílica e o sulfato de estrôncio. A barita possui aplicações industriais tais como lubrificante de broca na indústria de petróleo, como enchimento de filtros industriais, enchimento denso de plásticos, em freios e em alguns selantes e adesivos (IPCS-INCHEM, 2002).

A toxicocinética dos íons de bário é a mesma para seus sais e bases solúveis (cloreto, nitrato, carbonato, sulfeto, hidróxido). O sulfato de bário, insolúvel, não é absorvido no trato gastrintestinal (TGI) em condições rotineiras de administração (via oral como contraste radiopaco para radiografias, em doses que podem chegar até $450 \mathrm{~g} /$ por pessoa). Entretanto, pode ser parcialmente absorvido se houver lesão do TGI ou obstipação intestinal. Devido à limitada ou insignificante taxa de absorção intestinal e dérmica, espera-se que o sulfato de bário não exerça efeitos tóxicos ao organismo humano. Alguns compostos, como o nitrato e o hidróxido, são irritantes locais (pele, pulmões, TGI). Cerca de $30-50 \%$ do bário solúvel é absorvido pelo intestino. O bário é eliminado predominantemente nas fezes (90\%), sendo apenas cerca de $2 \%$ excretado por via renal. A meia-vida de eliminação pode variar de 3,6 a 1033 dias. Não sofre metabolismo. É depositado principalmente no esqueleto e eliminado primariamente nas fezes (após ser administrado por vias intra ou extravascular) (IPCS-INCHEM, 2002; KLAASSEN, et al., 1991; ELLENHORN, 1997).

O composto de bário mais utilizado em estudos biológicos é o cloreto de bário $\left(\mathrm{BaCl}_{2}\right)$, cuja solubilidade é de $375 \mathrm{~g} / \mathrm{L}$ em água a $20^{\circ} \mathrm{C}$. O carbonato apresenta baixa solubilidade em água, de $0,020 \mathrm{~g} / \mathrm{L}$, ainda assim quase 20 vezes mais solúvel que o sulfato de bário $\left(0,00115 \mathrm{~g} / \mathrm{L}\right.$, a $\left.20^{\circ} \mathrm{C}\right)$ (ELLENHORN, 1997).

Em relação à toxicidade aguda, a dose letal mediana (DL50) dos compostos solúveis de bário (cloreto, carbonato e sulfeto) varia desde 118 até $800 \mathrm{mg} / \mathrm{Kg}$, sendo que os sinais de intoxicação aguda em animais de experimentação incluem acúmulo de fluido na traquéia, inflamação intestinal, diminuição da razão de peso fígado/cérebro, escurecimento do fígado, aumento da razão de peso rim/peso corporal e diminuição do peso corporal. O carbonato de bário, devido à sua toxicidade aguda (DL50 de $200 \mathrm{mg} / \mathrm{kg}$ ), já foi empregado como princípio ativo de produto rodenticida (JOURDAN, et al., 2001; ELLENHORN, 1997).

A intoxicação aguda por sulfato de bário e por outros compostos do bário é rara, havendo limitadas citações na literatura internacional, envolvendo situações de tentativa de suicídio e até a utilização de derivado de bário por via intravascular (BLANC, et al., 1995; PÉLLISSER-ALICOT, et al., 1999; SAVRY, et al., 1999; JOURDAN, et al., 2001).

Dentre os sinais e sintomas de intoxicação, a exposição a compostos solúveis do bário pode levar a efeitos tóxicos em vários sistemas fisiológicos, incluindo o gastrintestinal (salivação, náusea, vômito, diarréia aquosa, 
intensa dor abdominal, aumento do peristaltismo ou movimento intestinal); o sistema nervoso (midríase, ansiedade, parestesia circumoral e periférica, diminuição de reflexos profundos de tendões, cefaléia, confusão e convulsão); o sistema respiratório (insuficiência respiratória e edema pulmonar); o sistema cardíaco (aumento da automaticidade ou do ritmo, hipertensão, arritmias - contrações ventriculares prematuras, prolongamento do intervalo QT, taquicardia ventricular, fibrilação ventricular e assistolia; e o sistema muscular (mioclonia, mialgias ou dores musculares, rigidez, paralisia, disartria ou dificuldade de articulação e paralisia flácida (com fraqueza muscular) (BLANC, et al., 1995; ELLENHORN, 1997; PÉLLISSER-ALICOT, et al., 1999; SAVRY, et al., 1999; JOURDAN, et al., 2001; IPCS-INCHEM, 2002).

É necessário fazer diagnóstico diferencial frente a outras circunstâncias que podem levar a sintomatologia semelhante àquela provocada pelo bário, tais como o envenenamento pelo peixe ciguatera, o envenenamento paralítico e neurotóxico pelo peixo Baiacu, botulismo, difteria, paralisia periódica hipocalêmica familiar, paralisia tirotóxica periódica, síndrome de Guillain-Barré e gastrenterite (ELLENHORN, 1997; IPCS-INCHEM, 2002).

A ingestão oral desde 0,8 a 1,5 g de composto solúvel do bário pode levar a paralisia por hipocalemia (diminuição do potássio) e morte. No Quadro 1, abaixo, apresentam-se alguns compostos solúveis do bário e suas doses tóxicas a humanos.

Quadro 1. Sinais da intoxicação a doses mínimas tóxicas e letais para compostos solúveis do bário (ELLENHORN, 1997; JOURDAN et al, 2000).

\begin{tabular}{|c|c|c|}
\hline Composto & Exposição & Efeito \\
\hline Carbonato de bário & $\begin{array}{c}\text { Dose mínima letal } \\
(57 \mathrm{mg} / \mathrm{Kg})\end{array}$ & Morte \\
\hline Carbonato de bário & $\begin{array}{l}\text { Menor dose tóxica } \\
(29 \mathrm{mg} / \mathrm{Kg})\end{array}$ & $\begin{array}{l}\text { Paralisia flácida sem anestesia, } \\
\text { parestesia, fraqueza muscular }\end{array}$ \\
\hline Cloreto de bário & $\begin{array}{l}\text { Dose mínima letal } \\
(11,4 \mathrm{mg} / \mathrm{Kg})\end{array}$ & Morte \\
\hline Cloreto de bário & $\begin{array}{l}\text { Menor dose tóxica } \\
\text { (a partir de } 2 \mathrm{mg} / \mathrm{Kg} \text { ) }\end{array}$ & $\begin{array}{l}\text { Vômito, diarréia, pirose, salivação, } \\
\text { vertigem, cianose, bradicardia, dor } \\
\text { torácica, tremores, convulsões, } \\
\text { arritmias cardíacas. }\end{array}$ \\
\hline Sulfeto de bário & $\begin{array}{l}\text { Menor dose tóxica } \\
(226 \mathrm{mg} / \mathrm{Kg})\end{array}$ & $\begin{array}{l}\text { Paralisia flácida sem anestesia, } \\
\text { fraqueza muscular, dispnéia }\end{array}$ \\
\hline
\end{tabular}

Fisiopatologicamente, o bário estimula inicialmente a musculatura estriada, cardíaca e lisa e diminui o potássio sérico, que é forçado a permanecer dentro das células. Na seqüência, há fraqueza muscular resultante da despolarização direta e bloqueio neuromuscular. Há outras causas tóxicas para a diminuição do potássio sérico (sobredosagem de teofilina, envenenamento por estricnina, uso de esteróides, tratamento com vitamina B12, exposição crônica a tolueno, intoxicação por salbutamol, administração de terbultalina) (ELLENHORN, 1997; IPCS-INCHEM, 2002).

Dentro de 1 a 2 horas após ingestão de algum composto solúvel de bário, os pacientes apresentam formigamento ao redor da boca, diarréia, vômito e dor abdominal intensa, tipo cólica. Usualmente observa-se também hipertensão arterial. Em 2 a 3 horas o formigamento migra para as faces e para as mãos, as reações pupilares são diminuídas ou impedidas, os reflexos musculares ficam deprimidos e flacidez muscular começa nas extremidades superiores e inferiores (ELLENHORN, 1997; IPCS-INCHEM, 2002).

Em alguns casos, quadriplegia flácida completa aparece dentro de poucas horas; em outros, a paralisia torna-se grave no segundo dia da intoxicação. A sensibilidade é sempre preservada. Na maioria dos casos os sintomas desaparecem em 24 horas e os pacientes podem receber alta em 48 horas. Em alguns pacientes a paralisia muscular e a fraqueza podem persistir por mais de uma semana. O prognóstico a longo prazo é favorável, mas a síndrome aguda, que pode incluir arritmia cardíaca, pode ser fatal e deve ser prontamente tratada. A morte pode sobrevir em poucas horas, devido a parada cardíaca e paralisia respiratória, a não ser que um vigoroso tratamento com administração de potássio intravenoso seja conduzido (ELLENHORN, 1997; IPCSINCHEM, 2002).

Como critério complementar de diagnóstico, a radiografia do abdômen deve indicar a presença de produto radiopaco no intestino delgado e cólon; concentrações sanguíneas de bário elevadas são bons indicadores de absorção de composto baritado.

O tratamento obedece, geralmente, aos seguintes passos: 1) Instituir medidas usuais de descontaminação gástrica (carvão ativado, vômito, lavagem gástrica). 2) Adicionar 5 a $10 \mathrm{~g}$ de sulfato de sódio na solução de lavagem gástrica ou na solução de xarope de ipeca. 3) Monitorar o ritmo cardíaco e o potássio sérico para estabelecer a evolução nas primeiras 24 horas. Em casos de intoxicação por bário reportados, o nível de potássio permanece baixo até que uma grande quantidade de cloreto de potássio é administrado. Bário e potássio parecem competir na sua interação com os canais de potássio. A administração de grande volume de fluido também contribui para retirar o bário dos canais de potássio, pelo aumento da diurese. 4) Administrar elevado volume de fluidos e monitorar a urina e o soro para buscar evidência de insuficiência renal. 5) O sulfato de magnésio (30 g) 
administrado por meio de tubo nasogástrico pode prevenir intoxicação mais grave, por precipitar o bário solúvel a sulfato de bário. 6) O bário é excretado predominantemente nas fezes. Por isso, existe incerteza em relação à eficiência da diurese, da diálise e da hemoperfusão como auxiliares no tratamento. 7) A hemodiálise diminui a meia-vida plasmática do bário e ajuda no retorno da força de contração muscular. 8) A hipocalemia é tratada com infusão de potássio (ELLENHORN, 1997; IPCS-INCHEM, 2002; AMDUR, et al., 1991).

Devido à raridade e à gravidade da intoxicação aguda por compostos de bário, é que este trabalho foi proposto, com o objetivo de investigar a toxicidade aguda através do screening hipocrático e avaliação do índice de letalidade do produto Marca $\mathrm{A}$, comparando-o a outros sais de bário solúveis (nitrato de bário, $\left.\mathrm{Ba}\left(\mathrm{NO}_{3}\right)_{2}\right)$ e carbonato de bário, $\mathrm{Ba}\left(\mathrm{CO}_{3}\right)_{2}$ ) e insolúvel (sulfato de bário puro, $\mathrm{BaSO}_{4}$ ).

\section{METODOLOGIA}

\section{Animais}

Foram utilizados camundongos Swiss (Mus musculus) machos, pesando em média $25 \mathrm{~g}$ e ratos Wistar (Rattus norvergicus), machos (300-430 g), não-isogênicos, alojados em gaiolas de polipropileno com água e ração à vontade e em perfeitas condições de saúde oriundas do Biotério Central da Universidade Federal de Goiás.

Os animais foram aclimatizados, no Núcleo de Estudos e Pesquisas Tóxico-farmacológicos da Faculdade de Farmácia da UFG (NEPET-UFG) pelo período mínimo de cinco dias para averiguação do comportamento, dos hábitos alimentares e fisiológicos e das condições sanitárias dos mesmos. Neste local, a temperatura média é controlada em $22 \pm 3^{\circ} \mathrm{C}$ e a umidade relativa do ar de $30-70 \%$, com ciclo claro/escuro (12h claro/ $12 \mathrm{~h}$ escuro) (BRITO, 1994).

A maravalha utilizada (de pinho-branco ou equivalente) foi autoclavada e, após o uso, trocada diariamente e descartada. As gaiolas são periodicamente desinfetadas com solução de gliceraldeído.

A alimentação dos animais foi feita com ração comercial de boa qualidade e adequada às necessidades nutritivas dos ratos, cujos nutrientes estão de acordo com a quantidade preconizada na literatura (NAS, 1978; KNAPKA, 1997). Os animais ficaram um período de cerca de 4 horas de jejum, antes dos tratamentos.

\section{Produtos químicos, reagentes, medicamentos}

Os produtos ensaiados foram Marca A, que é uma suspensão de sulfato de bário em água (BaSO 1 g/ml); nitrato de bário, $\mathrm{Ba}\left(\mathrm{NO}_{3}\right)_{2}$; carbonato de bário, $\mathrm{Ba}\left(\mathrm{CO}_{3}\right)_{2}$ e sulfato de bário, $\mathrm{BaSO}$, todos com grau analítico, provenientes do Laboratório de Análises Toxicológicas da Faculdade de Farmácia da UFG. À exceção do produto Marca A, todos os compostos de bário foram dissolvidos (nitrato e carbonato) ou suspenso (sulfato) em solução salina fisiológica, imediatamente antes da administração aos animais do experimento.

\section{Screening hipocrático e observação de letalidade}

Para a realização do screening hipocrático (MALONE, 1962; MALONE, 1977) e observação da letalidade, foram utilizados 2 a 3 ratos/dose A administração se deu por via per oral (p.o.; gavage) nas seguintes doses, em ratos: nitrato de bário, $\mathrm{Ba}\left(\mathrm{NO}_{3}\right)_{2}$ [400 e $800 \mathrm{mg} / \mathrm{kg}$ ]; carbonato de bário, $\mathrm{Ba}\left(\mathrm{CO}_{3}\right)_{2}$ [400 e $2000 \mathrm{mg} / \mathrm{kg}$ ], sulfato de bário, $\mathrm{BaSO}_{4} 4000$ [mg/kg] e Marca A [1000, 2000 e 4000 mg/kg]). Utilizou-se um grupo controle com dois animais, tratados com solução salina fisiológica, por gavage.

O screening hipocrático foi executado por meio de observações comportamentais sistemáticas, incluindo: atividade geral, frênito vocal, irritabilidade, resposta ao toque, resposta aperto cauda, contorção, posição trem posterior, reflexo endireitamento, tonus do corpo, força para agarrar, ataxia, reflexo auricular, reflexo corneal, tremores, convulsões, straub, hipnose, anestesia, lacrimação, ptose, micção, defecação, piloereção, hipotermia, respiração, cianose, hiperemia, morte) serão realizadas a intervalos variados no dia de administração da droga (10 min, 30 min, 1h, 2h, 4h, 6h, 12h e 24h) e, à partir de então, diariamente, até o décimo quarto dia (MALONE, 1962; MALONE, 1977).

Quanto aos camundongos, utilizaram-se 7 grupos de 10 camundongos, seguindo modelo clássico de Litchfield \& Wilcoxon, 1949 (vide Tabela 2). A administração também se deu via per oral (gavage) nas seguintes doses: carbonato de bário, $\mathrm{Ba}\left(\mathrm{CO}_{3}\right)_{2}\left[300\right.$ e $600 \mathrm{mg} / \mathrm{kg}$, sulfato de bário, $\mathrm{BaSO}_{4} 2000$ [mg/kg] e Marca A [1000, 2000 e $4000 \mathrm{mg} / \mathrm{kg}]$ ). Todos os animais foram observados por até 14 dias. Os animais controle receberam solução salina fisiológica, pela mesma via de administração, em volume adequado.

As doses utilizadas nos ensaios com os animais foram baseadas na dose usual de Marca $A$ em humanos (150 mL ou $150 \mathrm{~g}$ dose única, via oral); considerando peso médio de $75 \mathrm{~kg}$, o que redundou em $2 \mathrm{~mL}$ ou $2 \mathrm{~g} / \mathrm{kg} \mathrm{de}$ peso). Foi considerada, também a dose letal mediana (DL50) da literatura. 
$\mathrm{Na}$ Tabela 1 apresentam-se os dados obtidos após o tratamento de ratos Wistar machos, dose única por gavage, por substâncias solúveis e insolúveis do bário e e Marca A, e observação por até 14 dias para anotação de sinais de toxicidade (screening hipocrático) e letalidade. Já na Tabela 2 apresentam-se os resultados obtidos após o tratamento de camundongos machos, por gavage, para observação de letalidade.

Tabela 1. Ensaios de toxicidade aguda em ratos Wistar machos (screening hipocrático) de compostos do bário e do produto Marca A, administrados por gavage. Os animais foram observados por até 14 dias.

\begin{tabular}{|c|c|c|c|c|c|}
\hline Produto & $\begin{array}{c}\text { Dose } \\
(\mathrm{mg} / \mathrm{Kg})\end{array}$ & \begin{tabular}{|c|} 
DL50 \\
p.o. \\
$(\mathrm{mg} / \mathrm{Kg})$
\end{tabular} & Peso (g) & $\begin{array}{c}\text { Clínica } \\
\text { (sinais de toxicidade aguda em } 24 \text { h) }\end{array}$ & Letalidade \\
\hline $\begin{array}{l}\text { Nitrato de } \\
\text { bário }\end{array}$ & 400 & 200 & 300 & $\begin{array}{l}\text { Taquipnéia, irritabilidade, diarréia, tremores, astenia, } \\
\text { dispnéia, dificuldade de locomoção, eriçamento de pelo, } \\
\text { micção excessiva, rinorréia, irritação testicular e peniana, } \\
\text { redução de peso. }\end{array}$ & Não \\
\hline $\begin{array}{l}\text { Nitrato de } \\
\text { bário }\end{array}$ & 400 & 200 & 310 & $\begin{array}{l}\text { Taquipnéia, irritabilidade, diarréia, tremores, taquicardia, } \\
\text { astenia, dispnéia, dificuldade de locomoção, eriçamento de } \\
\text { pelo, micção excessiva, rinorréia, irritação testicular e } \\
\text { peniana, redução de peso. }\end{array}$ & Sim \\
\hline $\begin{array}{l}\text { Carbonato } \\
\text { de bário }\end{array}$ & 400 & 200 & 370 & $\begin{array}{l}\text { Tremores, taquipnéia, micção excessiva, dispnéia, } \\
\text { rinorréia e hemorragia nasal, pênis e testículos } \\
\text { proeminentes e inflamados. }\end{array}$ & Não \\
\hline $\begin{array}{l}\text { Carbonato } \\
\text { de bário }\end{array}$ & 800 & 200 & 428 & $\begin{array}{l}\text { Tremores, taquipnéia, micção excessiva, dispnéia, } \\
\text { rinorréia e hemorragia nasal. }\end{array}$ & $\begin{array}{l}\operatorname{Sim} \\
(24 \mathrm{~h})\end{array}$ \\
\hline Marca A & 1000 & $\mid-------$ & 308 & $\begin{array}{l}\text { Diminuição de reflexos, eriçamento de pelo, hemorragia } \\
\text { renal, diarréia, astenia, edema de pulmão, pênis e } \\
\text { testículos proeminentes e inflamados. }\end{array}$ & Não \\
\hline Marca A & 1000 & \begin{tabular}{|l|}
-------- \\
\end{tabular} & 320 & $\begin{array}{l}\text { Diminuição de reflexos, eriçamento de pelo, hemorragia } \\
\text { renal, diarréia, astenia, pênis e testículos proeminentes e } \\
\text { inflamados. }\end{array}$ & Não \\
\hline Marca A & 2000 & \begin{tabular}{|l|}
--------- \\
\end{tabular} & 420 & $\begin{array}{l}\text { Tremores, taquicardia, pênis e testículos proeminentes e } \\
\text { inflamados. }\end{array}$ & Não \\
\hline Marca A & 2000 & |-------- & 392 & $\begin{array}{l}\text { Tremores, insuficiência respiratória, piloereção } \\
\text { (hipotermia), sem resposta ao toque, taquicardia. }\end{array}$ & $\begin{array}{l}\text { Sim } \\
(7 \mathrm{~h})\end{array}$ \\
\hline Marca A & 2000 & \begin{tabular}{|l|}
-------- \\
\end{tabular} & 432 & $\begin{array}{l}\text { Diminuição de reflexo postural, flacidez muscular, } \\
\text { taquicardia, taquipnéia, diarréia, astenia. }\end{array}$ & $\begin{array}{l}\operatorname{Sim} \\
(21 h)\end{array}$ \\
\hline Marca A & 4000 & \begin{tabular}{|l|}
--------- \\
\end{tabular} & 395 & $\begin{array}{l}\text { Tremores, taquicardia, flacidez muscular (reflexo de } \\
\text { endireitamento afetado, decúbito dorsal), paralisia } \\
\text { muscular, pênis e testículos proeminentes e inflamados. }\end{array}$ & Não \\
\hline Marca A & 4000 & \begin{tabular}{|l|}
-------- \\
\end{tabular} & 435 & $\begin{array}{l}\text { Tremores, insuficiência respiratória, contorção, piloereção } \\
\text { (hipotermia), sem resposta ao toque, taquicardia. }\end{array}$ & $\begin{array}{l}\text { Sim } \\
(9 h)\end{array}$ \\
\hline $\begin{array}{l}\text { Sulfato de } \\
\text { bário }\end{array}$ & 4000 & \begin{tabular}{|l|}
-------- \\
\end{tabular} & 312 & $\begin{array}{l}\text { Animal alerta, reflexos normais, sem diarréia ou rinorréia. } \\
\text { Ao final de } 14 \text { dias, apresentou bom estado de saúde e } \\
\text { ganho de peso. }\end{array}$ & Não \\
\hline $\begin{array}{l}\text { Sulfato de } \\
\text { bário }\end{array}$ & 4000 & \begin{tabular}{|l|}
--------- \\
\end{tabular} & 340 & $\begin{array}{l}\text { Animal alerta, reflexos normais, sem diarréia ou rinorréia. } \\
\text { Ao final de } 14 \text { dias, apresentou bom estado de saúde e } \\
\text { ganho de peso. }\end{array}$ & Não \\
\hline
\end{tabular}

Os ratos tratados com $\mathrm{Ba}\left(\mathrm{NO}_{3}\right)_{2}, \mathrm{Ba}\left(\mathrm{CO}_{3}\right)_{2}$ e Marca $\mathrm{A}$ apresentaram sinais de intoxicação dosedependentes.

Os seguintes sinais foram observados: tremores, eriçamento de pêlo, rinorréia, taquicardia, taquipnéia, diarréia, diminuição de reflexo de endireitamento, flacidez e paralisia muscular. Os pênis e os testículos dos ratos apresentaram-se proeminentes e inflamados. 
Observou-se letalidade em $50 \%$ dos ratos tratados com doses crescentes de Marca A, sendo que a dose de $1000 \mathrm{mg} / \mathrm{kg}$ não levou à morte nenhum animal utilizado, o que ocorreu nas doses de 2000 e $4000 \mathrm{mg} / \mathrm{kg}$, correspondentes a uma (1) e a duas (2) vezes a dose utilizada para um humano médio.

Os animais tratados com dois sais solúveis do bário, o nitrato e o carbonato, apresentaram intensos sinais de intoxicação e, nos dois grupos, houve morte de metade dos animais tratados com doses superiores à DL50. Os ratos tratados com sulfato de bário p.a. mantiveram-se normais, inclusive com ganho de peso, ao final do período de observação.

Tabela 2. Teste de toxicidade aguda em camundongos suíços, machos, dose única, per oral (gavage), com o produto Marca A, o sulfato de bário e o carbonato de bário (este em dose proporcional à existente na forma de contaminação do produto com o mesmo - 13,8\%).

\begin{tabular}{|l|l|l|l|l|l|}
\hline Grupo & \multicolumn{1}{|c|}{ Produto } & \multicolumn{1}{c|}{$\begin{array}{c}\text { Dose } \\
(\mathbf{m g} / \mathbf{k g})\end{array}$} & \multicolumn{1}{c|}{$\begin{array}{c}\text { No } \\
\text { animais }\end{array}$} & \multicolumn{1}{|c|}{ Morte } & Letalidade (\%) \\
\hline I & Marca A & 1000 & 10 & 1 & 10 \\
\hline II & Marca A & 2000 & 10 & 1 & 10 \\
\hline II & Marca A & 4000 & 10 & 5 & 50 \\
\hline IV & Sulfato de bário & 2000 & 10 & 0 & 0 \\
\hline V & Carbonato de bário & 300 & 10 & 0 & 0 \\
\hline VI & Carbonato de bário & 600 & 10 & 4 & 40 \\
\hline VII & Solução salina 0,9\% & ----- & 10 & 0 & 0 \\
\hline
\end{tabular}

Verificou-se letalidade nos camundongos administrados com os seguintes produtos: $\mathrm{Ba}\left(\mathrm{NO}_{3}\right)_{2}(800 \mathrm{mg} / \mathrm{kg})$,

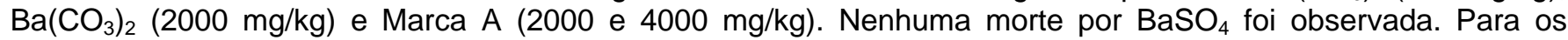
camundongos, as doses de 1000 e $2000 \mathrm{mg} / \mathrm{kg}$ de Marca A foram letais para 10\% dos animais e a dose de 4000 $\mathrm{mg} / \mathrm{kg}$ levou à letalidade $50 \%$ dos animais.

Através destes dados pode-se inferir que a administração de sulfato de bário (sal insolúvel em água) foi segura e não apresentou toxicidade nas doses administradas, não foi letal a nenhum dos animais e não provocou nenhum sinal clínico anormal. Ao mesmo tempo, a administração de nitrato de bário e carbonato de bário (sais solúveis em água) foi letal na maioria das doses, gerou sinais patofisiológicos nos animais, o que evidencia um quadro de intoxicação.

Igual comportamento foi verificado quando se administrou o Marca A, o que é indicativo da presença de sais solúveis de bário neste medicamento, vindo este ensaio a corroborar com o resultado da análise química do produto Marca A, realizada no Instituto de Química da UFG, que constatou a presença de carbonato de bário em teor de 13,8\%. O carbonato de bário é um sal solúvel do bário, tendo sido empregado como raticida (JOURDAN, 2001; ELLENHORN, 1997) e para o qual existem relatos de casos de intoxicações agudas graves e até letais (PÉLLISSER-ALICOT, et al., 1999; JOURDAN, et al., 2001; ELLENHORN, 1997; SAVRY, et al., 1999).

Muitos pacientes fizeram uso de mais de um frasco de Marca A para a realização da radiografia, dobrando a dose e aumentando o risco de letalidade e de sequelas decorrentes da exposição ao contraste.

Conforme pode ser observado nas tabelas 1 e 2, nos ensaios de toxicidade com derivados do bário e com o produto do lote condenado do Marca A, doses elevadas (igual e 2 vezes à dose para humanos) de sulfato de bário p.a. não levaram nem ratos e nem camundongos à morte, enquanto que, o carbonato de bário conseguiu levar à letalidade 1 rato e 40\% dos camundongos experimentados; enquanto isso, doses variadas de Marca A (1000 a $4000 \mathrm{mg} / \mathrm{Kg}$ ) levaram à morte $50 \%$ dos ratos tratados e até $50 \%$ dos camundongos experimentados; aqueles que não morreram desenvolveram sinais claros de intoxicação aguda. Mesmo sem realizar nenhum teste estatístico, fica evidente a toxicidade do Marca A, corroborando com os resultados laboratoriais do INCQS-FIOCRUZ (Mensagem N $N^{\circ} 771$ do Instituto Nacional de Controle de Qualidade em Saúde), sabe-se que o produto Marca A apresentou altas quantidades de carbonato, sulfeto e sulfato de bário em sua composição. Já no Instituto de Química da UFG foi dosado, no produto Marca A, 13,8\% de carbonato de bário (solúvel em água) na formulação do lote do contraste condenado.

Desta forma, julgando estarem corretos os nexos clínicos e epidemiológicos (considerando as aplicações dos princípios da epidemiologia de avaliar pessoa, tempo e lugar), pelos resultados laboratoriais e pela observação do efeito tóxico do produto Marca A em ratos e camundongos, é possível inferir que o produto do lote supracitado levou a quadros de intoxicação aguda e, inclusive, letalidade.

\section{CONCLUSÃO}


O produto Marca A apresentou efeitos semelhantes aos sais solúveis (nitrato e carbonato) em decorrência de contaminação por 13,8\% de carbonato de bário (solúvel; DL50 $200 \mathrm{mg} / \mathrm{kg}$ ) no contraste, enquanto que o sulfato de bário mostrou-se inócuo em doses equivalentes.

Ensaios biológicos de toxicidade são úteis no esclarecimento de intoxicações humanas, acidentais ou intencionais.

Os ensaios de toxicidade aguda acima descritos, bem como uma ampla revisão crítica da literatura, subsidiaram ações do Ministério Público Federal de Goiás, em favor dos pacientes e de seus familiares, demonstrando ser eficientes em auxiliar no diagnóstico confirmatório do agente causal da intoxicação provocada pelo contraste radiológico.

\section{REFERÊNCIAS BIBLIOGRÁFICAS}

AMDUR, M. O.; DOULL, J.; KLAASSEN, C. D. Casarett and Doull's Toxicology. 4th ed. New York: Editora Pergamon Press, 1991.

BLANC, P.; CARBAJAL, R.; PAUPEN, A.; LENCLEN, R.; COUDERC, S.; OLIVIER-MARTIN, M. Intoxication par l'eau après une preparation pour un lavement baryté. Archives de Pédiatrie. v. 2, p. 871-873, 1995.

BRITO, A. S. Manual de Ensaios Toxicológicos In Vivo. Campinas: Editora da UNICAMP, 1994.

Centers for Disease Control and Prevention/Morbidity and Mortality Weekly Report (CDC/MMWR), v. 53, n. 43, p. 1047-1048, 2003.

ELLENHORN, M. J. Ellenhorn's Medical Toxicology - Diagnosis and Treatment of Human Poisoning. $2^{\mathrm{a}}$ ed. Baltimore: Editora Williams \& Wilkins, 1997.

International Program of Chemical Safety (IPCS-INCHEM) (ONU, ILO, WHO): Concise International Chemical Assessment Document 33, 2001. CD ROM 2002-2003.

JOURDAN, S.; BERTONI, M.; SERGIO, P.; MICHELE, P.; ROSSI, M. Suicidal poisoning with barium chloride. Forensic Science International. v. 119, p. 263-265, 2001.

KNAPKA, J. J. Diet selection and formulation in Laboratory animal science: Laboratory animal studies in the quest of health and knowledge. Editors: Rotschild, H.A., Rosenkranz, A. and Moura Duarte, F,A., Rev. Bras. Genética, Ribeirão Preto-SP, 1997.

LITCHFIELD, J. T.; WILCOXON, F. Simplified method evoluation dose-effect experiments. Journal of Pharmacology and Experimental Therapeutics. v. 96, p. 99-113, 1949.

MALONE, M. H. "Pharmacological Approaches to Natural Products Screening and Evaluation" in New Natural Products and Plant Drugs with Pharmacological, Biological or Therapeutical Activity, Edited by Wagner, H. and Wolff, P. - pp. 23 53; Spriger-Verlag, Berlin , 1977.

MALONE, M. H.; ROBICHAUD, R. C. A hippocratic screening for pure or drug materials. Lloydia, v.25, p.320-332, 1962.

National Academy of Sciences (NAS): Report of the committee on laboratory animal diets. Control of diets in laboratory experimentation. ILAR News $21 \mathrm{n}^{\circ}$ 2: 5-12, 1978.

Organisation for Economic Co-operation and Development (OECD), Guideline 407: Acute Oral Toxicity: Modified Up-and-Down Procedure, 2006.

PÉlisSeR-ALICOT, A. L.; LÉONETTI, G.; ChAMPSAUR, P.; ALLAIN, P.; MAURAS, Y.; BOtTA, A. Fatal poisoning due to intravasation after oral administration of barium sulfate for contrast radiography. Forensic Science International. v. 106, p. 109-113, 1999.

SAVRY, C.; BOUCHE, O.; LEFRANT, J. Y.; SAISSY, G.; ALLAIN, P. Intoxication par sulfate de baryum? Annales Francaises d'Anesthésie et de Réanimation. v. 17, p. 454-457, 1999. 